\title{
Melt processing of polymer biocomposites
}

\author{
Juliana França Marinho', Natália Ferreira Braga', Annelise Krohn¹, Fernanda Salviano Myata1, \\ Luiz Henrique Silveira ${ }^{1}$, Abner Cabral Neto ${ }^{1}$ and Guilhermino José Macêdo Fechine ${ }^{2}$
}

\author{
${ }^{1}$ Departmento de Engenharia de Materiais, Escola de Engenharia, \\ Universidade Presbiteriana Mackenzie - UPM, São Paulo, SP, Brazil \\ ${ }^{2}$ Centro de Pesquisa sobre Grafeno e Nano-Materiais - Mackgraphe, \\ Universidade Presbiteriana Mackenzie - UPM, São Paulo, SP, Brazil \\ *guilherminojmf@mackenzie.br
}

\begin{abstract}
A coupled device extruder and injection moulding were used to prepare biocomposites in order to provide a continuous and large-scale production, and overcome the fiber degradation inside the extruder. Two types of biocomposites were prepared, Sisal/poly(buthylene adipate-co-terephthlate) - PBAT and Juta/poly(lactide acid)/poly(buthylene adipateco-terephthlate) blend. The biocomposites were prepared with fiber as-received and alkaline treated. The mechanical properties of biocomposites were increased by the fibers content; and the alkaline treatment was efficient to promote a good adhesion between fiber and polymer. In the case of the Juta fiber, the alkaline treatment used was too strong and led to fiber degradation. The results presented here show an alternative and continuous process to obtain biocomposites with relevant mechanical properties using fiber roving and avoiding fiber degradation.
\end{abstract}

Keywords: biocomposite, natural fibers, PBAT, PLA/PBAT, alkaline treatment.

\section{Introduction}

The lower performance in mechanical properties is the main problem of some biodegradable polymers. One of the solutions for that is biocomposites prepared with some fillers and biodegradable polymer ${ }^{[1-4]}$. Most of the biocomposites acquired from natural fibers and biodegradable polymers are produced by solvent evaporation or hot compression ${ }^{[5-8]}$. For industrial purposes and large scale production the first choice is not appropriated and hot compression is limited to the size of the machine. Both choices are a not continuous process. Melt mixing is the best choice for the large scale production and it provides a homogenous mix of polymer matrix and fibers. Several researchers have been used internal mixer and extruder to prepared biocomposites ${ }^{[9-11]}$. Nonetheless, during melt mixing biocomposite preparation the fiber length and its integrity could be affected due to high temperatures and high rates of shear at extruder or mixer. A coupled device extruder and injection moulding were used here to prepare biocomposites in order to provide a continuous large-scale production process and avoid the fiber degradation inside the extruder.

\section{Experimental Section}

The polymers used were poly(buthylene adipate-coterephthlate) - PBAT and poly(lactide acid)/poly(buthylene adipate-co-terephthlate) - PLA/PBAT blend with Melt Volume-flow Rate (MVR) of 4 and $10 \mathrm{ml} / 10 \mathrm{~min}$, respectively. The fibers used in this work were Sisal and Juta roving without any purification. Two types of biocomposites were prepared: Sisal + PBAT and Juta + PLA/PBAT blend. The biocomposites were prepared with fibers as received and fibers submitted to alkaline treatment ${ }^{[12]}$. Fibers were mixed with the polymers by a coupled device extruder located after the matrix to protect fibers against high rates of shear and producing fiber-polymer pellets. The fiber contents on these pellets were $17.5 \pm 3.5$ and $9.2 \pm 1.5$ for Sisal + PBAT and Juta + PLA/PBAT blend, respectively. At least 5 fiber-polymer pellets were used for the fiber content calculation. Firstly, the samples were weighted and after that immersed in tetrahydrofuran $\left(40^{\circ} \mathrm{C}\right)$ until complete dissolution. The solutions were filtered and the fibers were dried and weighted. The pulling speed of the fiber during the covering by the polymer was adjusted according to the melting viscosity of each polymer; consequently, the fiber content of fiber-polymer pellets for each kind of pellet is different. The fiber is located in the center of the pellets covered by the polymer (Figure 1a). The extruder device could not be shown here because it will be submitted to Patent analysis. Two compositions were prepared for each biocomposite. 1. 100\% of "fiber-polymer pellets"; $2.50 \%$ of "fiber-polymer pellets" plus $50 \%$ of neat polymer. The same compositions were prepared with treated fibers. The composition and designations of all samples are presented on Table 1. The same procedure used for calculation of fiber content with the fiber-polymer pellets was also used for the injected samples, with at least 5 pieces of each biocomposite. Injection-moulded samples were produced according to ASTM D638 for tensile tests. Extrusion $(30 \mathrm{rpm})$ and injection process were carried out at temperatures below $200{ }^{\circ} \mathrm{C}$ to avoid fiber thermodegradation. For tensile strength measurements were conducted at $100 \mathrm{~mm} / \mathrm{min}$ at $25^{\circ} \mathrm{C}$. After tensile testing the fractured surfaces of the specimens were observed using a JEOL JSM-6510 Scanning Electron Microscope operating at $15-20 \mathrm{kV}$. 


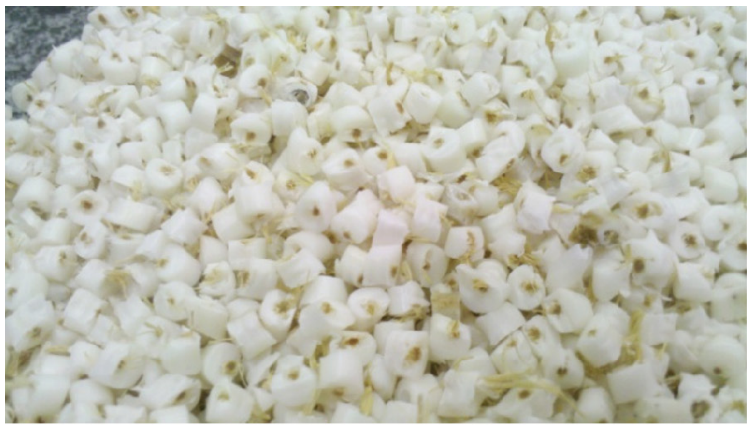

(a)

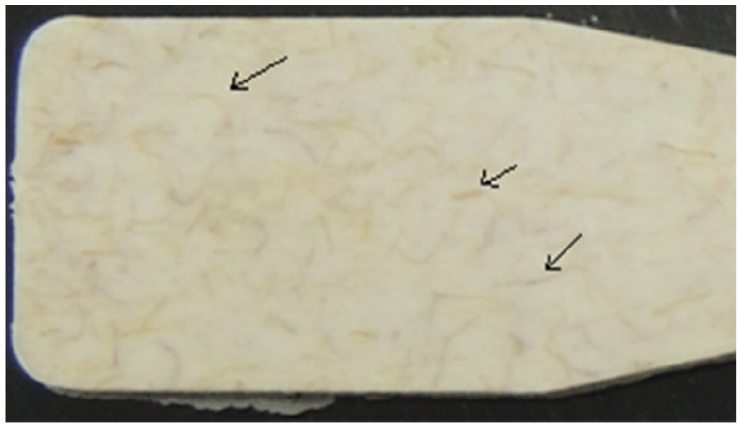

(b)

Figure 1. Photography of PLA/PBAT + Juta fibers pellets produced by coupled device extruder (a); Photography of PLA/PBAT + Juta fibers sample produced by injection moulding (b).

Table 1. Designation and composition of all biocomposites and neat polymers

\begin{tabular}{clc}
\hline Sample & \multicolumn{1}{c}{ Composition of the pellets } & Designation \\
\hline 1 & $100 \%$ PBAT & PBAT \\
3 & $50 \%$ PBAT/Sisal fiber no treated $+50 \%$ PBAT & Biocomposite 1 \\
4 & $100 \%$ PBAT/Sisal fiber no treated & Biocomposite 3 \\
5 & $50 \%$ PBAT/Sisal fiber treated $+50 \%$ PBAT & Biocomposite 4 \\
6 & $100 \%$ PBAT/Sisal fiber treated & PLA/PBAT \\
7 & $100 \%$ PLA/PBAT & Biocomposite 5 \\
8 & $50 \%$ PLA/PBAT/Sisal fiber no treated $+50 \%$ PLA/PBAT & Biocomposite 6 \\
10 & $100 \%$ PLA/PBAT/Sisal fiber no treated & Biocomposite 8 \\
\hline
\end{tabular}

\section{Results and Discussion}

The methodology used here has two steps: extrusion and injection moulding. The fiber-polymer pellets were produced in the first step (extrusion). During the second step the fibers-polymer pellets were melted at high level of shear (injection). The surface image of the Biocomposite 5 (Figure 1b) shows the fibers dispersed on the matrix. The same behavior was observed for all biocomposites. Table 2 shows the values of fiber contents calculated by the dissolution of the injected biocomposites samples.

Mechanical properties results and fiber content are presented on Table 2 . The rigidity of the PLA/PBAT blend even at lower fiber content produced biocomposites with high values of Elastic Modulus and Yield Stress. As presented on Table 2, there is a positive tendency in Elastic Modulus and Yield Stress following the inclusion of the fiber and its content increasing for PBAT systems. Meanwhile, the fiber treatment has no significant influence on these properties. The presence of the Sisal fiber and its content increasing led to the decrease of Yield Strain values as expected and published before for others systems since the fibers increases the rigidity of the composites ${ }^{[13]}$. At the same time, the Yield Strain is improved with the fiber treatment for biocomposites. These results indicate an improvement in adhesion between fiber and matrix as several researchers had already presented with others matrix and fibers ${ }^{[13]}$. A different behavior is found for Juta + PLA/PBAT. The presence of fiber and the increase of its content does not show any good correlation with mechanical properties. However, the treatment of Jute fiber leads to a negative effect on the mechanical properties, unlike what happened with Sisal fiber.

The Yield Strain data from Biocomposites 5 to 8 also show that the fiber treatment was not efficient to promote a good adhesion between the fiber and matrix or it was very intense and the fiber was degraded. Mechanical tests were performed with Sisal and Juta fibers before and after treatment. Tensile test conducted with the Sisal fiber has its value of stress at the breakpoint maintained around 155 $\mathrm{MPa}$ even after treatment; whereas, Jute fiber lost $30 \%$ of this property. These results confirm one of the aspects supposed before.

Figures $2 \mathrm{a}$ and $2 \mathrm{~b}$ show an example of the interface between fiber and matrix for biocomposites 1 and 2, respectively, without treatment. Even without being treated, the fiber remains linked to the matrix after tensile test. After treatment (biocomposites 3 and 4 - Figures 2c and $2 \mathrm{~d}$, respectively), the Sisal fiber still has a good adhesion with PBAT matrix leading to stress transfer, consequently an improvement in mechanical properties.

Tensile fractured surface of untreated and alkalitreated PLA/PBAT-Juta biocomposites are shown on Figures 2e to $2 \mathrm{~h}$. It is obvious that untreated Juta fiber and matrix present a poor adhesion and the fiber can be easily pulled-out. A great gap between fiber and matrix could be observed on both biocomposites. Figures $2 \mathrm{~g}$ and $2 \mathrm{~h}$ show an example of the interface between fiber and matrix for biocomposites 7 and 8. No gap is observed on these two micrographs. The adhesion between Juta fiber and PLA/PBAT blend was enhanced by the fiber treatment. Similar results were 
Table 2. Mechanical properties results of all biocomposites and neat polymers.

\begin{tabular}{ccccc}
\hline Sample & $\begin{array}{c}\text { Fiber Content } \\
\mathbf{( \% )}\end{array}$ & $\begin{array}{c}\text { Elastic Modulus } \\
(\mathbf{M P a})\end{array}$ & $\begin{array}{c}\text { Yield stress } \\
\mathbf{( M P a )}\end{array}$ & $\begin{array}{c}\text { Yield strain } \\
\mathbf{( \% )}\end{array}$ \\
\hline PBAT & & $80.3 \pm 7.5$ & $7.1 \pm 0.5$ & $20.6 \pm 3.4$ \\
Biocomposite 1 & $13.3 \pm 3.5$ & $122.0 \pm 14.6$ & $7.9 \pm 0.6$ & $11.8 \pm 1.5$ \\
Biocomposite 2 & $16.7 \pm 4.1$ & $236.6 \pm 12.7$ & $8.5 \pm 0.2$ & $9.0 \pm 0.9$ \\
Biocomposite 3 & $13.4 \pm 2.5$ & $118.2 \pm 4.8$ & $7.9 \pm 0.4$ & $19.1 \pm 0.6$ \\
Biocomposite 4 & $18.3 \pm 5.1$ & $192.5 \pm 32.9$ & $8.1 \pm 0.9$ & $16.0 \pm 1.1$ \\
PLA/PBAT & & $825.8 \pm 68.6$ & $18.1 \pm 0.7$ & $6.8 \pm 0.8$ \\
Biocomposite 5 & $4.9 \pm 0.9$ & $867.5 \pm 76.3$ & $16.5 \pm 0.3$ & $5.6 \pm 0.9$ \\
Biocomposite 6 & $10.1 \pm 1.1$ & $1462.4 \pm 204.1$ & $20.5 \pm 0.6$ & $2.5 \pm 0.3$ \\
Biocomposite 7 & $4.2 \pm 0.7$ & $752.6 \pm 57.1$ & $9.9 \pm 1.4$ & $2.7 \pm 0.2$ \\
Biocomposite 8 & $7.7 \pm 0.7$ & $1178.7 \pm 104.6$ & $7.4 \pm 0.8$ & $1.8 \pm 0.2$ \\
\hline
\end{tabular}

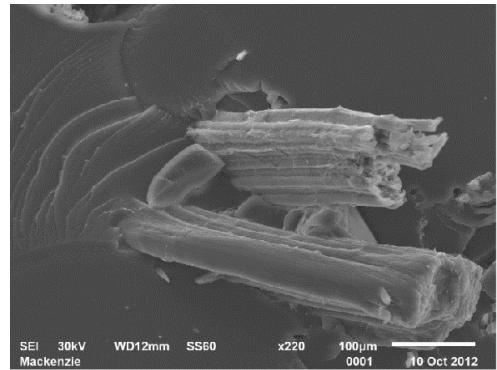

(a)

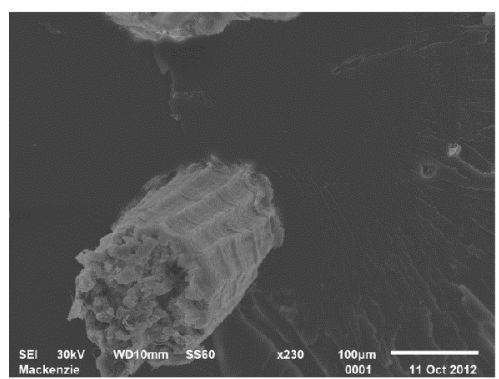

(d)

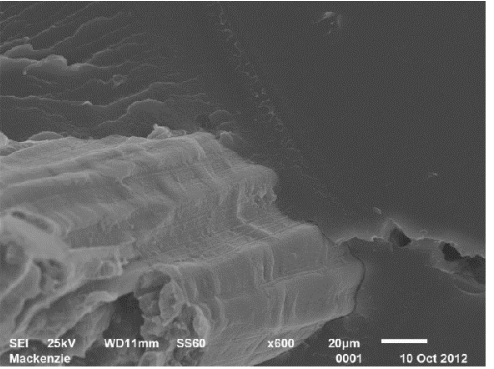

(b)

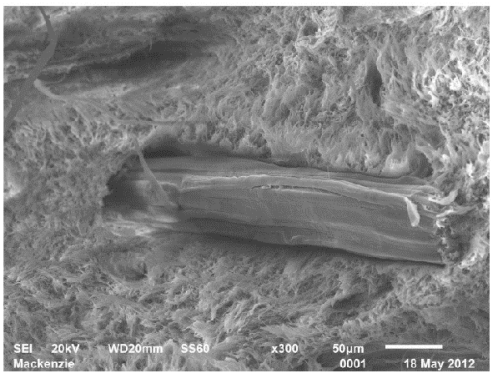

(e)

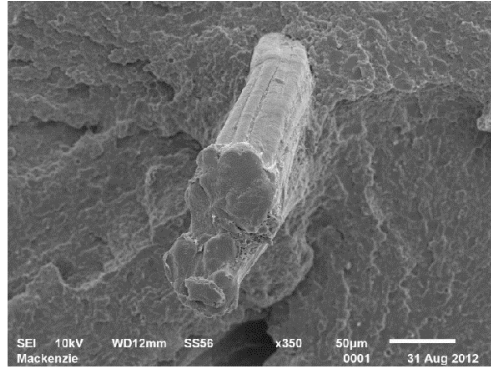

(c)

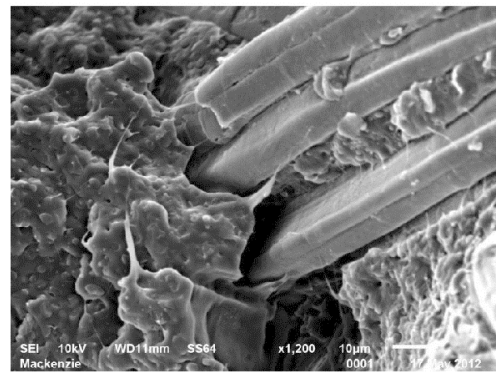

(f)

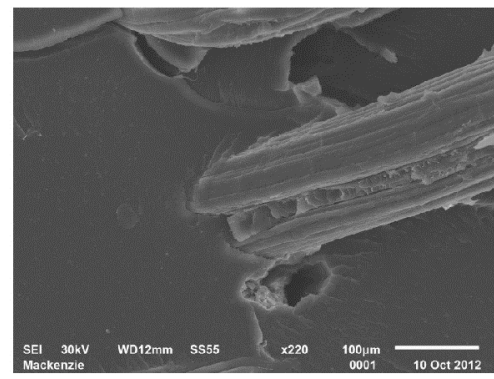

(g)

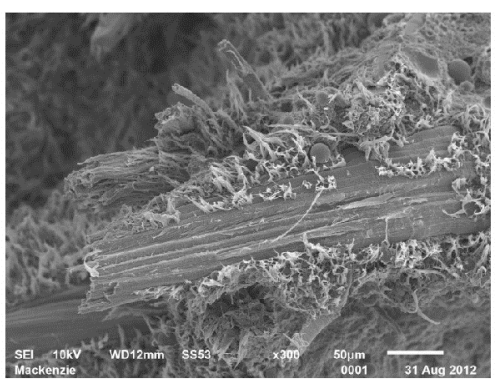

(h)

Figure 2. Tensile fractured surface of untreated ( $a$ and b) and alkalitreated PBAT-Sisal biocomposites (c and d) and untreated (e and f) and alkalitreated PLA/PBAT-Juta biocomposites ( $\mathrm{g}$ and $\mathrm{h}$ ).

observed for alkaline treatment in coir fiber in order to improve the interface fiber-matrix of the poly(butylene succinate) + coir fiber biocomposites ${ }^{[12]}$.

In the case of Juta fiber, the treatment with $\mathrm{NaOH}$ was enough to improve the adherence but it led to degradation of the fiber. The results presented just confirm the supposition that the treatment was good for the compatibility but intense for the Jute fiber in terms of degradation.

\section{Conclusions}

A coupled device extruder and injection moulding were used to produce biocomposites with natural fibers (Sisal and Jute) and biodegradable polymers (PBAT and PLA/PBAT blend). The presence of the fibers increased the Elastic Modulus and Yield Stress of the neat polymers. Tensile fracture surface microscopies show that the alkaline 
treatment was efficient to promote a good adhesion for both fibers. However, the alkaline treatment on the Juta fiber was too strong and fiber degradation could also be observed. The results show that the methodology used here is an alternative and continuous process to obtain biocomposites with relevant mechanical properties using fiber roving and avoiding fiber degradation.

\section{Acknowledgements}

The authors are grateful to FAPESP and CNPq (Brazilian funding agencies) for the financial support.

\section{References}

1. John, M., \& Thomas, S. (2008). Biofibres and biocomposites. Carbohydrate Polymers, 71(3), 343-364. http://dx.doi. org/10.1016/j.carbpol.2007.05.040.

2. Plackett, D., Andersen, T. L., Pedersen, W. B, \& Nielsen, L. (2003). Biodegradable composites based on 1-polylactide and jute fibres. Composites Science and Technology, 63(9), 12871296. http://dx.doi.org/10.1016/S0266-3538(03)00100-3.

3. La Mantia, F. P., \& Morreale, M. (2011). Green composites: A brief review. Composites. Part A, Applied Science and Manufacturing, 42(6), 579-588. http://dx.doi.org/10.1016/j. compositesa.2011.01.017.

4. Rosa, M. F., Chiou, B.-S., Medeiros, E. S., Wood, D. F., Williams, T. G., Mattoso, L. H. C., Orts, W. J., \& Imam, S. H. (2009). Effect of fiber treatments on tensile and thermal properties of starch/ethylene vinyl alcohol copolymers/coir biocomposites. Bioresource Technology, 100(21), 5196-5202. http://dx.doi. org/10.1016/j.biortech.2009.03.085. PMid:19560341

5. Matkó, S., Toldy, A., Keszei, S., Anna, P., Bertalan, G., \& Marosi, G. (2005). Flame retardancy of biodegradable polymers and biocomposites. Polymer Degradation \& Stability, 88(1), 138145. http://dx.doi.org/10.1016/j.polymdegradstab.2004.02.023.

6. Coombes, A. G. A., Verderio, E., Shaw, B., Li, X., Griffin, M., \& Downes, S. (2002). Biocomposites of non-crosslinked natural and synthetic polymers. Biomaterials, 23(10), 2113-
2118. http://dx.doi.org/10.1016/S0142-9612(01)00341-6. PMid:11962651

7. Corradini, E., Imam, S., Agnelli, J. M., \& Mattoso, L. C. (2009). Effect of coconut, sisal and jute fibers on the properties of starch/gluten/glycerol matrix. Journal of Polymers and the Environment, 17(1), 1-9. http://dx.doi.org/10.1007/s10924009-0115-1.

8. Nadhan, A. V., Rajulu, A. V., Li, R., Jie, C., \& Zhang, L. (2012). Properties of regenerated cellulose short fibers/cellulose green composite films. Journal of Polymers and the Environment, 20(2), 454-458. http://dx.doi.org/10.1007/s10924-011-0398-x.

9. Lemos, A. L., \& Martins, R. M. (2014). Desenvolvimento e caracterização de compósitos poliméricos à base de poli (ácido lático) e fibras naturais development and characterization of polymeric composites. Polímeros: Ciência e Tecnologia, 24, 190-197. http://dx.doi.org/10.4322/polimeros.2014.047.

10. Santos, E. F., Moresco, M., Rosa, S. M. L., \& Nachtigall, S. M. B. (2010). Extrusão de compósitos de PP com fibras curtas de coco : efeito da temperatura e agentes de acoplamento. Polímeros: Ciência e Tecnologia, 20, 215-220. http://dx.doi. org/10.1590/S0104-14282010005000036.

11. Santos, P. A., Spinacé, M. A. S., Fermoselli, K. K. G., \& De Paoli, M.-A. (2009). Efeito da forma de processamento e do tratamento da fibra de curauá nas propriedades de compósitos com poliamida-6. Polímeros: Ciência e Tecnologia, 19, 31-39. http://dx.doi.org/10.1590/S0104-14282009000100010.

12. Nam, T. H., Ogihara, S., Tung, N. H., \& Kobayashi, S. (2011). Effect of alkali treatment on interfacial and mechanical properties of coir fiber reinforced poly(butylene succinate) biodegradable composites. Composites. Part B, Engineering, 42(6), 16481656. http://dx.doi.org/10.1016/j.compositesb.2011.04.001.

13. Li, X., Tabil, L. G., \& Panigrahi, S. (2007). Chemical treatments of natural fiber for use in natural fiber-reinforced composites: a review. Journal of Polymers and the Environment, 15(1), 25-33. http://dx.doi.org/10.1007/s10924-006-0042-3.

Received: July 17, 2014

Revised: Nov. 24, 2014

Accepted: Jan. 09, 2015 